\title{
Retrograde Synaptic Transmitter of Endocannabinoid System - A Neuromodulatory Pathway
}

\author{
Divya $\mathbf{R}^{1}$, Ashok $\mathbf{V}^{2}$ and Rajajeyakumar $\mathbf{M}^{3 *}$ \\ ${ }^{1}$ Department of Physiology, Karpagam Faculty of Medical Sciences and Research, \\ Chennai, India \\ ${ }^{2}$ Department of Biochemistry, Karpagam Faculty of Medical Sciences and Research, \\ Chennai, India \\ Editorial \\ Volume 4 Issue 1 \\ Received Date: February 23, 2019 \\ Published Date: March 11, 2019 \\ DOI: $10.23880 /$ nnoaj-16000131 \\ ${ }^{3}$ Department of Physiology, Trichy SRM Medical College Hospital \& Research Centre, Chennai, India \\ *Corresponding author: Rajajeyakumar M, Assistant professor, Department of Physiology, SRM Medical College Hospital \\ \& Research Centre, Trichy, MGR Medical University, Chennai, Tamil Nadu, India, Tel: +09751382650; Email: \\ rajakumar60@gmail.com
}

Abbreviations: ECS: Endocannabinoid System; CNS: Central Nervous System; eCBs: Endogenous Cannabinoids; 2-AG: 2-Arachidonoyl Glycerol; TRPV1: Transient Receptor Potential Vanilloid Receptor type 1.

\section{Introduction}

\begin{abstract}
Synaptic Neurotransmission \& Retrograde Messengers: Neurotransmission across the Synapse is through the mechanism of release of neurotransmitters from the presynaptic junction, neurotransmitter that is released gets transported towards the postsynaptic terminal, where the receptors are situated. These neurotransmitters bind with the concerned receptors and activate them. Whereas in retrograde transmission, the signalling includes a diffusible messenger that is liberated from the postsynaptic element. This neurotransmitter travels "backwards" across the synaptic cleft, where it stimulates the presynaptic terminal receptors. The Receptors for retrograde messengers are generally present on or near the presynaptic nerve terminals, and their stimulation causes a modification in synaptic transmitter release. This type of retrograde neurotransmitters is involved in long-term synaptic plasticity and also has a significant role in the short-term regulation of synaptic transmission [1].
\end{abstract}

ECS (Endocannabinoid System): The endocannabinoid system (ECS) is an extensive neuro modulatory arrangement that plays imperative roles in the maturation and development of the central nervous system. They also play a major role in synaptic plasticity, the response to endogenous and environmental insults. The ECS encompasses cannabinoid receptors, endogenous cannabinoids (endocannabinoids), and the enzymes responsible for the synthesis and degradation of the endocannabinoids [2].

Cannabinoid Receptors: CB1 and CB2 are the cannabinoid. Of which the most abundant cannabinoid receptors are the CB1 cannabinoid receptors. These cannabinoids also engage the transient receptor potential channels, and peroxisome proliferator activated receptors [2]. $\mathrm{CB}_{1}$ receptors are plentiful in the central nervous system (CNS), principally in cortex, cerebellum, basal ganglia and hippocampus. $\mathrm{CB}_{2}$ receptors are located in microglia and vascular elements which are at much lower levels in the CNS compared to $\mathrm{CB}_{1}[3]$.

Cannabinoids: Tetrahydrocannabinol is the exogenous cannabinoids that binds with the cannabinoid receptors in the body. The endogenous cannabinoids (eCBs) are produced inside the human body. They are 2-AG (2arachidonoyl glycerol), anandamide (a rachidonoyl ethanolamide) [2].

Endocannabinoid Signalling: The principal mechanism of action by which eCBs controls the synaptic 


\section{Neurology \& Neurotherapy Open Access Journal}

function is through the retrograde signalling. The postsynaptic activity leads to the production of an eCB that moves retrograde or backwards across the synapse and then binds with the presynaptic $\mathrm{CB}_{1}$ Receptors. This suppresses the release of neurotransmitter (Figure A). The endocannabinoids also produce autocrine signalling in a non-retrograde manner. By this mechanism of action, they can modify neural function and synaptic transmission due to the binding with $\mathrm{CB}_{1}$ Receptors and TRPV1 (transient receptor potential vanilloid receptor type 1) which are located on or within the postsynaptic terminal (Figure B). Recent research also proves that the endocannabinoids also signals through the astrocytes which modify the presynaptic or postsynaptic function indirectly (Figure C) [4].

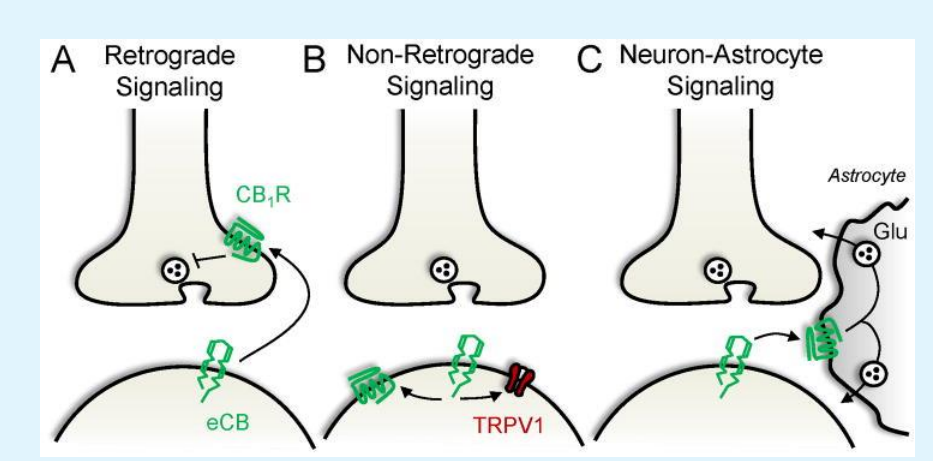

Figure: Endocannabinoid signalling at the synapse [4].

\section{References}

1. Alger BE (2002) Retrograde signaling in the regulation of synaptic transmission: focus on endocannabinoids. Prog Neurobiol 68(4): 247-286.

2. Lu HC, Mackie K (2015) An Introduction to the Endogenous Cannabinoid System. Biol Psychiatry 79(7): 516-525.
3. Mackie K (2005) Distribution of cannabinoid receptors in the central and peripheral nervous system. Handb Exp Pharmacol (168): 299-325.

4. Castillo PE, Younts TJ, Chávez AE, Hashimotodani Y (2012) Endocannabinoid signaling and synaptic function. Neuron 76(1): 70-81. 